Check for updates

Cite this: RSC Adv., 2019, 9, 11745

Received 6th February 2019

Accepted 1st April 2019

DOI: $10.1039 / c 9 r a 00989 b$

rsc.li/rsc-advances

\section{Dissociative adsorption modes of TATB on the Al (111) surface: a DFT investigation $\dagger$}

\author{
Guo-zheng Zhao, (iD *a Hui-li Li, ${ }^{a}$ Jian-feng Jia, ${ }^{a}$ Hai-shun Wu ${ }^{a}$ and Ming Lu ${ }^{b}$
}

Herein, the adsorption modes and electronic structures of TATB/AI (111) systems were investigated using the density functional theory (DFT) approach. We found that chemical adsorption led to the decomposition of the TATB molecule on the Al surface by four adsorption modes. All the adsorption configurations were accompanied by fractures of the $\mathrm{N}-\mathrm{O}$ bonds in the nitro groups. In addition, there was a hydrogen atom transfer for 5P. For parallel and vertical adsorptions, the TATB molecules favored planar or quasi-planar structures. The order of total energy with BSSE correction matches well with the order of adsorption energy. The absolute values of energy and adsorption energy of $6 \mathrm{P}$ and $6 \mathrm{~V}$ are highest in the parallel and vertical adsorption systems, respectively. Electrons are transferred from the Al (111) surface to the TATB molecule; this results in the activation of TATB on the Al (111) surface and obvious augmentation of the PDOS (partial density of states) peaks of the $\mathrm{N}$ and $\mathrm{O}$ atoms. From the Al (111) surface to the TATB molecule, the transfer of the electrons of $4 \mathrm{P}(14.00 \mathrm{e})$ and $6 \mathrm{~V}(9.04 \mathrm{e})$ is largest for the parallel and vertical adsorptions, respectively.

\section{Introduction}

TATB was reported for the first time in 1888 by Jackson and Wing. ${ }^{1}$ Subsequently, the crystal structure ( $P \overline{1}$ space group) of TATB was obtained and characterized by Cady et al. ${ }^{2}$ Over the past few decades, 1,3,5-triamino-2,4,6-trinitrobenzene (TATB), a major representative of nitro explosives, ${ }^{3,4}$ has been extensively used in many areas as an energetic material; ;,6 the intramolecular and intermolecular hydrogen bonding interactions are relatively stronger in TATB, which contribute to its exceptional insensitivity to thermal, impact, friction, and shock, as compared to those in traditional energetic materials such as 2,4,6-trinitrotoluene (TNT), 1,3,5-trinitrohexahydro-s-triazine (RDX), and octahydro-1,3,5,7-tetranitro-1,3,5,7-tetrazocine (HMX). Thus, significant experimental and theoretical investigations have been focused on TATB. ${ }^{7-9}$ Numerous investigations have been focused on its thermal decomposition and structural details, and several possibilities have been introduced for the decomposition pathways of TATB; however, the universal mechanism of these reactions is still unknown.

The transformation of intermolecular hydrogen is a possible initial step, which is suggested by theoretical calculations, in the thermal and shock decomposition process of crystal TATB. ${ }^{10-12}$ Based on quantum chemical methods, both

${ }^{a}$ Key Laboratory of Magnetic Molecules, Magnetic Information Materials Ministry of Education, The School of Chemistry and Material Science, Shanxi Normal University, Linfen 041004, PR China. E-mail: zhaoguozheng99@126.com

${ }^{b}$ School of Chemical Engineering, Nanjing University of Science and Technology, Nanjing 210094, China

† Electronic supplementary information (ESI) available. See DOI: 10.1039/c9ra00989b molecular and crystalline processes have been analysed by Kuklja et al., who discovered that $\mathrm{C}-\mathrm{NO}_{2}$ fission is the main pathway for the initial decomposition of TATB in the gas phase and on the (001) surface at high temperatures. ${ }^{\mathbf{1 3 4 1 4}}$ The formation of free radicals, which was examined by $\mathrm{Xu}$ et al., probably occurred during the photolysis of TATB. ${ }^{15}$ Goddard et al. predicted that the formation of large carbonaceous clusters was initiated by the decomposition of TATB by applying the firstprinciple-based ReaxFF reactive force field. ${ }^{16}$ Their research was mainly focused on the TATB molecule and crystal under different conditions. However, explosives, propellants, and pyrotechnics are made up of a variety of components, which interact with each other, and due to the influence of other components, TATB shows different dissociation modes. Apart from the questionable state of TATB, it is believed that its dissociation mode is also related to its interface structures. Liu and Wang et al. investigated 1,1-diamino-2,2-dinitroethene (FOX-7)-solvent interfacial interactions and found that hydrogen bonds and vdW interactions play a dominant role in the interaction between the solvent and FOX-7 surfaces. ${ }^{17}$ The interactions between the 3-nitro-1,2,4-triazole-5-one (NTO) crystal and solvent were studied by Li et al., who reported that the solvent adsorption on NTO occurs mainly via the solventcrystal face interactions of hydrogen bonding. ${ }^{18}$

To improve the performance of high energetic materials, aluminum (Al) powder is widely used as a metallic additive to explosives, propellants, and pyrotechnic compositions. ${ }^{19,20}$ As is known, $\mathrm{Al}$ can improve the energy toward the burning reaction in propellants and strengthen the blast effect of explosives. ${ }^{21,22}$ The size of $\mathrm{Al}$ particles plays a dominant role in the efficiency of these processes. Due to its large surface area, Al nanopowder can 
dramatically improve the performance of some energetic materials. ${ }^{2324}$ Additionally, the burn rate is improved remarkably by incorporating $\mathrm{Al}$ nanopowder in propellants. $\mathrm{Al}$ is also widely used in formulations of propellants and explosives; thus, it is of great importance to explore its reactions with energetic molecules. ${ }^{25}$ Ammunition composed of TATB and aluminum powder shows excellent performance. To understand the interaction mode of TATB/Al systems, comprehensive knowledge about the interface and electronic structure of the system is necessary. The interface between RDX and $\mathrm{Al}$ with different oxide layers was studied by Jaramillo-Botero et al. to understand the effect of nanosized $\mathrm{Al}$ on the thermal decomposition of $\mathrm{RDX}^{26}$ Bean et al. prepared $\mathrm{Al}$ enriched 1,1-diamino-2,2-dinitroethylene (Al-FOX-7) crystals to improve the friction sensitivity and detonation properties of the FOX-7 crystal. $^{27}$ Zhou et al. studied the diffusion of $\mathrm{NH}_{2} \mathrm{NO}_{2}$ molecules on the surface of $\mathrm{Al}$ under different temperatures and pressures. $^{28}$ The (111) surface of the Al crystal is easily exposed, decomposed and chemically corroded..$^{29,30}$ In contrast, to date, no theoretical work has been reported on the dissociative adsorption of TATB on the Al (111) surface. In the present study, we focused our investigation on the adsorption mode of TATB/Al (111). We elucidated the interaction mechanism and discussed the electronic structures and charge distributions of TATB on $\mathrm{Al}$ (111) surface.

\section{Computational details}

DFT calculations were performed using the CP2K software package based on the gradient-corrected functional of a revised Perdew-Burke-Ernzerhof functional (PBEsol). ${ }^{31,32}$ The initial Al crystal was introduced by Cooper. ${ }^{33}$ To build the $\mathrm{Al}$ (111) surface, a $4 \times 4 \times 4$ supercell of $\mathrm{Al}$ was optimized with the lattice parameters $a=b=c=4.057 \AA$, which match well with the reported values $(a=b=c=4.050 \AA) .{ }^{33} \mathrm{~A} 5 \times 5$ slab was constructed based on the optimized $\mathrm{Al}$ cell, which ensured that the distance between TATB and its period replica was larger than 7 A. Four Al layers were included and the vacuum region along the $c$ direction was larger than $15 \AA$. Fig. 1 illustrates the top and lateral views of the $5 \times 5$ surface model. The detailed lattice parameters and atomic coordinates of the $\mathrm{Al}$ (111) surface are listed in the ESI. $\dagger$ With the aim of finding the most stable TATB/Al (111) configuration, many types of adsorption sites were analyzed. The calculation details are listed in the ESI. $\dagger$

\section{Results and discussion}

\subsection{Adsorption mode of TATB/Al (111)}

Chemical adsorption causes the decomposition of the TATB molecule on the $\mathrm{Al}$ surface, which makes the dissociative adsorption extremely complicated. ${ }^{34,35}$ There are four adsorption modes, as follows:

(1) $\mathrm{C}_{6} \mathrm{~N}_{3} \mathrm{H}_{6}+3 \mathrm{NO}_{2} \rightarrow \mathrm{C}_{6} \mathrm{~N}_{3} \mathrm{H}_{6}+2 \mathrm{NO}+2 \mathrm{O}+\mathrm{NO}_{2}$ (Fig. 2 and 3; 1P, 2P, 6V).

(2) $\mathrm{C}_{6} \mathrm{~N}_{3} \mathrm{H}_{6}+3 \mathrm{NO}_{2} \rightarrow \mathrm{C}_{6} \mathrm{~N}_{3} \mathrm{H}_{6}+3 \mathrm{NO}+3 \mathrm{O}$ (Fig. 2; 3P, 4P, 6P).

(3) $\mathrm{C}_{6} \mathrm{~N}_{3} \mathrm{H}_{6}+3 \mathrm{NO}_{2} \rightarrow \mathrm{C}_{6} \mathrm{~N}_{3} \mathrm{H}_{6}+\mathrm{NO}+\mathrm{N}+3 \mathrm{O}+\mathrm{NO}_{2}$ (Fig. 2; $5 \mathrm{P})$.

(4) $\mathrm{C}_{6} \mathrm{~N}_{3} \mathrm{H}_{6}+3 \mathrm{NO}_{2} \rightarrow \mathrm{C}_{6} \mathrm{~N}_{3} \mathrm{H}_{6}+\mathrm{N}+2 \mathrm{O}+2 \mathrm{NO}_{2}$ (Fig. 2 and 3; $1 \mathrm{~V}, 2 \mathrm{~V}, 3 \mathrm{~V}, 4 \mathrm{~V}, 5 \mathrm{~V})$.

According to the center and $\mathrm{C}-\mathrm{C}$ symmetric axis of the benzene ring relative to the $\mathrm{Al}$ (111) surface, $\mathrm{P}$ and $\mathrm{V}$ denote parallel and vertical adsorptions of TATB, respectively, as listed in Fig. 2 and 3. Each stable form of TATB/Al (111) represents the top view of the optimized adsorption configuration after full relaxation of the atomic positions. Selected bond lengths, atomic distances and adsorption energies of different TATB/Al (111) are shown in Tables 1 and 2, respectively. For the parallel adsorption configurations, the dissociation of the TATB molecule can be shown in three ways, with the products of $\mathrm{NO}+$ $\mathrm{O}, \mathrm{NO}+\mathrm{O}+\mathrm{NO}_{2}$, and $\mathrm{NO}+\mathrm{O}+\mathrm{N}+\mathrm{NO}_{2}$, and for the vertical adsorption configurations, the dissociation of the TATB molecule can be shown in two ways, with the products of $\mathrm{NO}+\mathrm{O}+$ $\mathrm{NO}_{2}$, and $\mathrm{N}+\mathrm{O}+\mathrm{NO}_{2}$. The TATB molecules in our study prefer planar structures, which lay flat on the $\mathrm{Al}$ (111) surfaces.

For the twelve TATB/Al (111) adsorption systems, the order of total energy with BSSE correction is consistent with the order of adsorption energy, indicating that the total energy is closely related to the adsorption energy. The energies of the parallel

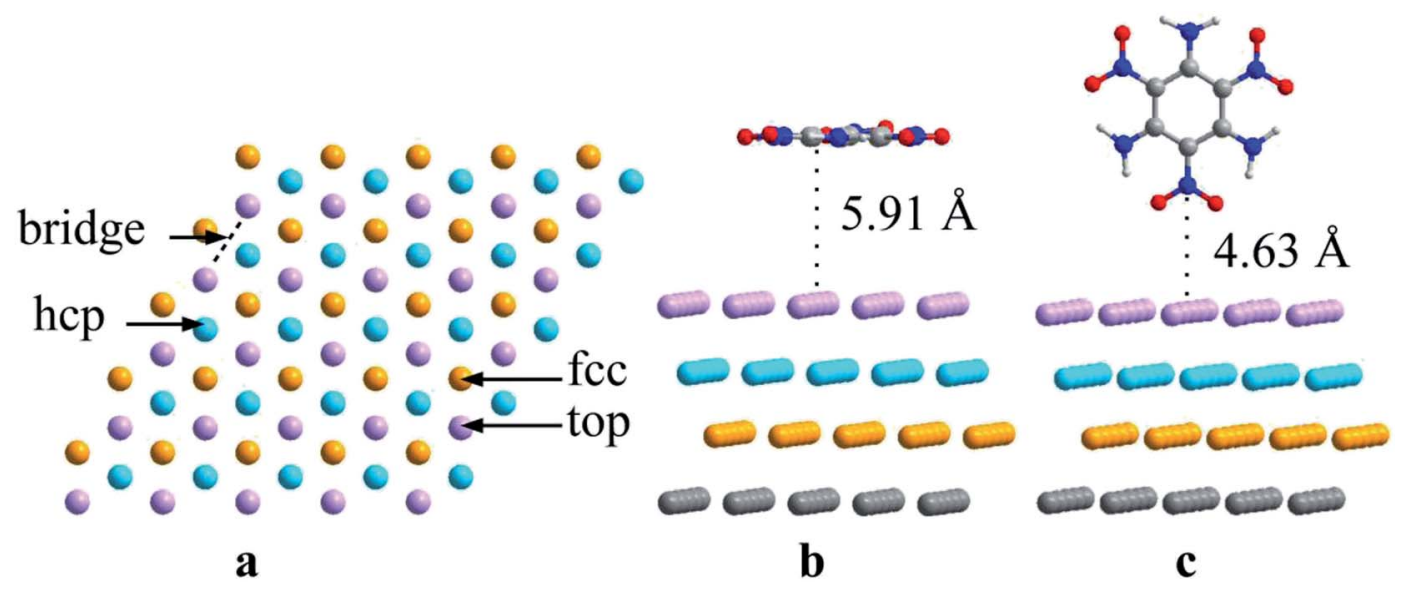

Fig. 1 (a) Top view of the sites depicted on the surface, (b) parallel TATB on the Al (111) surface with no interactions and (c) vertical TATB on the Al (111) surface with no interactions. 

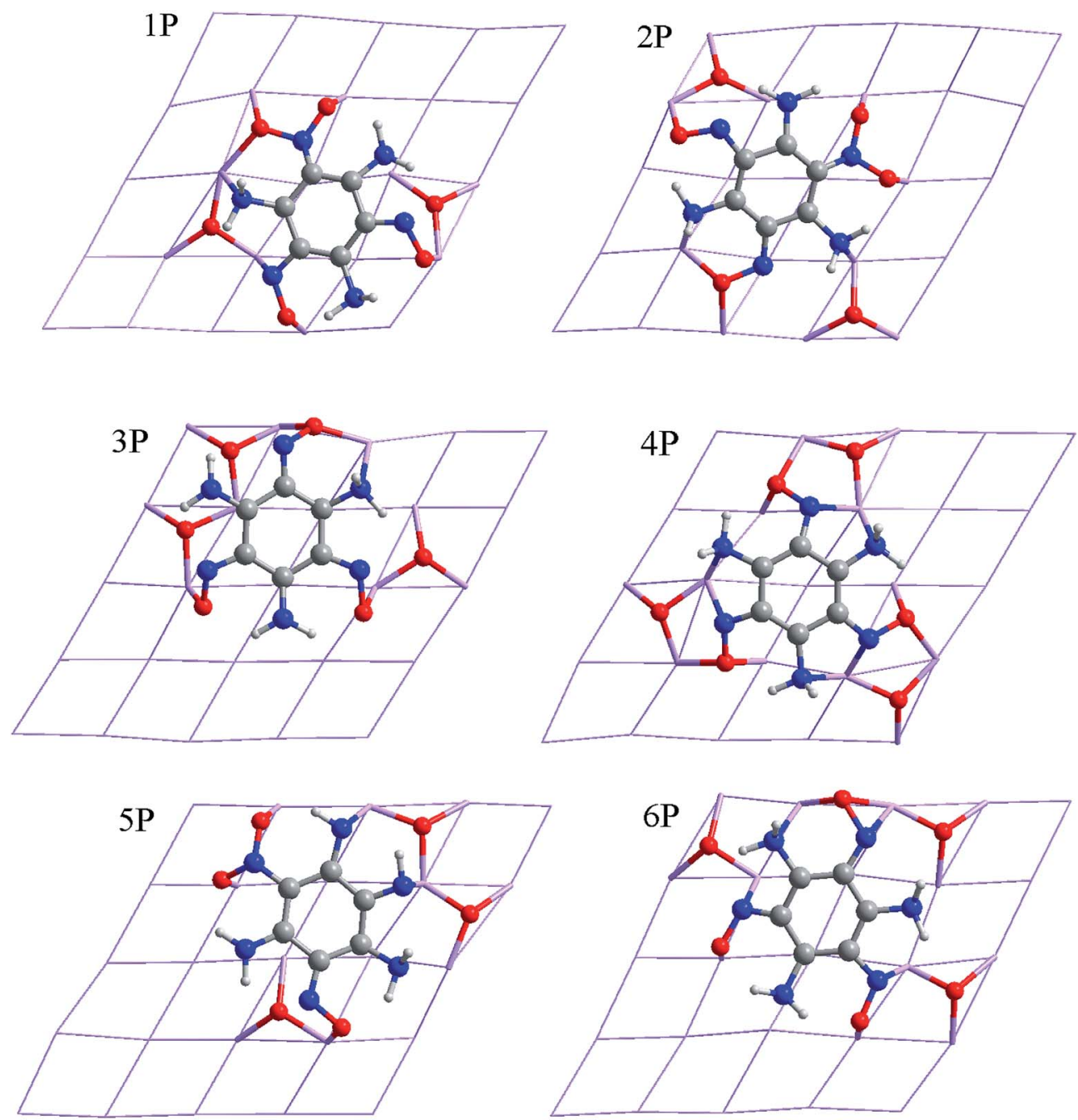

Fig. 2 Adsorption configurations of TATB/Al (111) obtained from optimized parallel configurations: 1P, 2P, 3P, 4P, 5P, and 6P denote the center of the benzene ring above a bridge site between the second layer of $\mathrm{Al}$, a bridge site between the third layer of $\mathrm{Al}$, an $\mathrm{fcc}$ site, an on-top site, an hcp site, and a bridge site between the first layer of Al, respectively.

and vertical adsorption are in the range of -398.339594 a.u. to -398.163630 a.u. and -398.151305 a.u. to -398.053016 a.u., respectively, which indicate that the parallel adsorption configurations are more stable than the vertical adsorption configurations, and therefore, the adsorption modes of these systems are inclined to parallel adsorption. The adsorption configurations are the most stable in the dissociation mode (2), which are all parallel adsorption, and the adsorption configurations are the most unstable in the dissociation mode (4), which are all vertical adsorption. Since the TATB molecule decomposition products of $3 \mathrm{P}, 4 \mathrm{P}, 5 \mathrm{P}$ and $6 \mathrm{P}$ are four radical species, their corresponding adsorption energies are higher than that of three radical species. From Table 2, the adsorption energies of $1 \mathrm{P}-6 \mathrm{P}$ are much higher than that of $\mathrm{P}$ $\left(-25.65 \mathrm{~kJ} \mathrm{~mol}^{-1}\right)$, and the adsorption energies of $1 \mathrm{~V}-6 \mathrm{~V}$ are much higher than that of $\mathrm{V}\left(-48.66 \mathrm{~kJ} \mathrm{~mol}^{-1}\right)$, indicating that the TATB/Al (111) adsorption systems are more stable than $\mathrm{P}$ and $\mathrm{V}$. Therefore, the $\mathrm{Al}$ atoms are oxidized easily by the radical species, which form stable $\mathrm{Al}-\mathrm{O}$ and $\mathrm{Al}-\mathrm{N}$ bonds.
The lying structure of $6 \mathrm{P}$ in Fig. 2 is confirmed to be the lowest energy (-398.339594 a.u.) configuration for TATB/Al (111), and an oxygen atom is dissociated from each nitro group in dissociation mode (2). The first layer of aluminum is no longer flat, and two aluminum atoms are much closer to the TATB molecule. Four Al-N bonds and thirteen Al-O bonds are formed, which have bond lengths of 1.995-2.099 $\AA$ and 1.806$1.960 \AA$, respectively. In comparison to the isolated TATB structure in Fig. 1(b) (i.e., there is no interaction between the TATB molecule and $\mathrm{Al}$ atoms on the surface), there is an irregular change for the $\mathrm{N}-\mathrm{H}$ bond of the amino group. For example, the N4-H41 bond is stretched from $1.042 \AA$ to $1.049 \AA$ and the N6-H61, N6-H62, and N4-H42 bonds are shortened to 1.039, 1.034, and $1.036 \AA$, respectively. The $\mathrm{N}-\mathrm{O}$ bond lengths augment further to a certain degree, which why the $\mathrm{N}$ and $\mathrm{O}$ atoms interact strongly with the $\mathrm{Al}$ atoms on the surface. For $6 \mathrm{P}$, the adsorption energy value is $-1877.67 \mathrm{~kJ} \mathrm{~mol}^{-1}$, which is the lowest among the twelve TATB/Al (111) adsorption systems. For $3 \mathrm{P}$, both the $\mathrm{O}$ and $\mathrm{N}$ atoms of $-\mathrm{NO}_{2}$ and $\mathrm{N}$ atoms of $-\mathrm{NH}_{2}$ with 

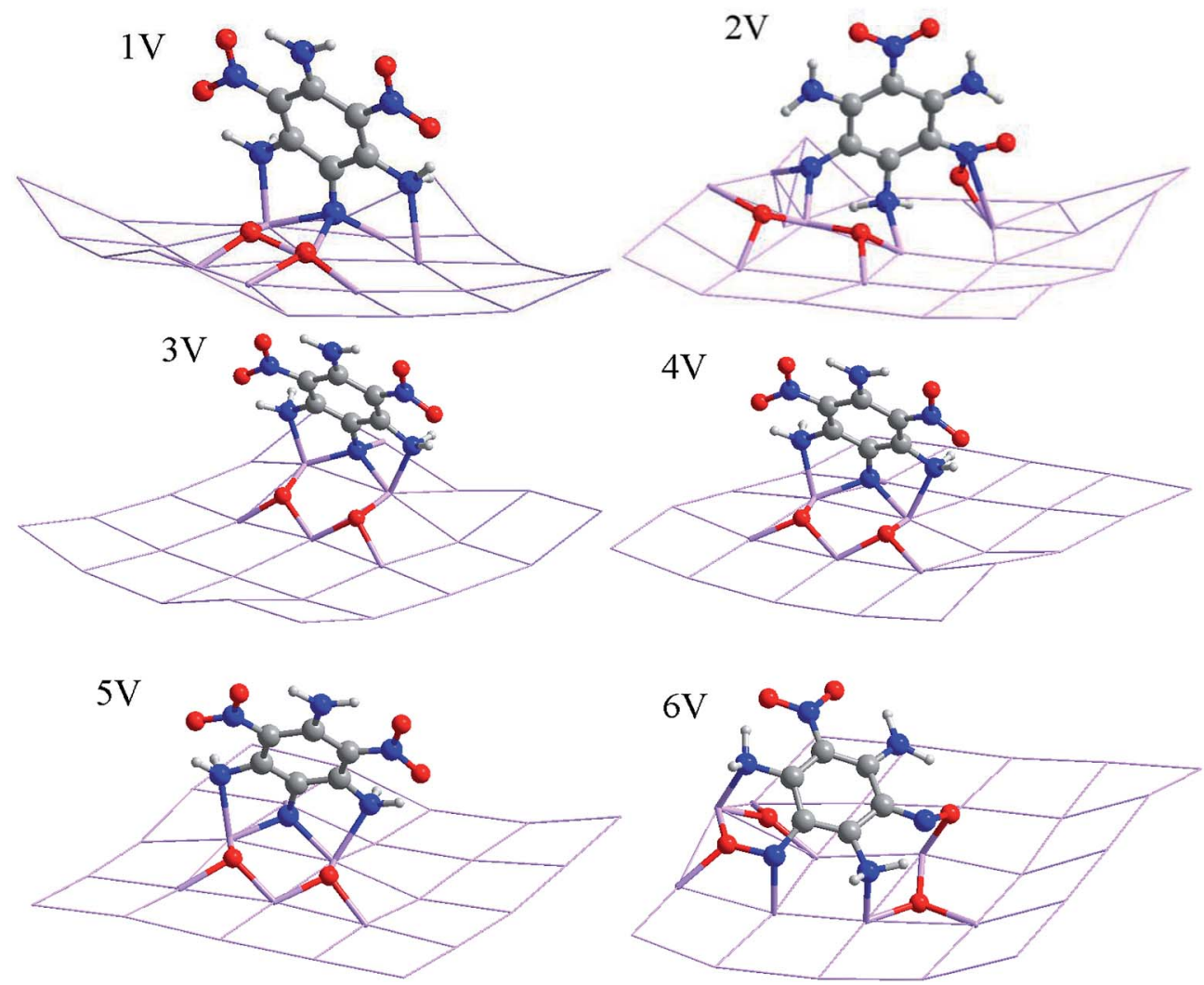

Fig. 3 Adsorption configurations of TATB/Al (111) obtained from the optimized vertical configurations: $1 \mathrm{~V}, 2 \mathrm{~V}, 3 \mathrm{~V}, 4 \mathrm{~V}, 5 \mathrm{~V}$, and $6 \mathrm{~V}$ denote the C-C symmetric axis of the benzene ring above an on-top site, a bridge site between the second layer of $\mathrm{Al}$, an fcc site, an hcp site, a bridge site between the third layer of $\mathrm{Al}$, and the first layer of $\mathrm{Al}$, respectively.

$\mathrm{Al}$ atoms form one $\mathrm{Al}-\mathrm{N}$ bond $(2.092 \AA)$ and thirteen $\mathrm{Al}-\mathrm{O}$ bonds (1.811-1.919 $\AA$ ) and for $4 \mathrm{P}$, both $\mathrm{O}$ and $\mathrm{N}$ atoms of $-\mathrm{NO}_{2}$ and $\mathrm{N}$ atoms of $-\mathrm{NH}_{2}$ with $\mathrm{Al}$ atoms form six $\mathrm{Al}-\mathrm{N}$ bonds with the length of 1.957-2.089 $\AA$ and fifteen $\mathrm{Al}-\mathrm{O}$ bonds with the length of 1.811-2.068 $\AA$. The lengths of the $\mathrm{N}-\mathrm{H}$ and $\mathrm{N}-\mathrm{O}$ bonds of $3 \mathrm{P}$ and $4 \mathrm{P}$ are longer than that of the isolated TATB molecule. $1 \mathrm{P}$ and $2 \mathrm{P}$ in Fig. 2 describe the case in which TATB is detached into $\mathrm{C}_{6} \mathrm{~N}_{3} \mathrm{H}_{6}, 2 \mathrm{NO}, 2 \mathrm{O}$, and $\mathrm{NO}_{2}$. For $1 \mathrm{P}$, two $\mathrm{Al}-\mathrm{N}$ and eleven $\mathrm{Al}-$ O bonds form with the lengths of 1.990-2.054 $\AA$ and 1.820-2.073 $\AA$, respectively. For $2 \mathrm{P}$, three $\mathrm{Al}-\mathrm{N}$ and eleven $\mathrm{Al}-\mathrm{O}$ bonds form with the lengths of 2.005-2.097 $\AA$ and 1.816-1.993 $\AA$, respectively. The formation of a large number of Al-O bonds significantly activates the dissociated oxygen atoms.

As shown in Fig. 3, $6 \mathrm{~V}$ shows vertical adsorption at the bridge site between the first layer of the $\mathrm{Al}$ surface. $6 \mathrm{~V}$ is the most stable structure in the vertical adsorption system studied, and its energy value is -398.151305 a.u., which illustrates the dissociation of one of the $\mathrm{O}$ atoms from two nitro groups. The adsorption and dissociation mode of $6 \mathrm{~V}$ agree better with that of $1 \mathrm{P}$. One of the dissociated oxygen atoms is embedded in the aluminum surface, and the first layer of aluminum atoms is extremely uneven, showing that there is strong interaction between TATB and the Al surface. As a result, the ТАTB molecular skeleton is approximately parallel to the aluminum surface, which achieves the transition from vertical adsorption to parallel adsorption. This result corresponds well with the fact that the adsorption mode of the system is inclined to parallel adsorption. Nine $\mathrm{Al}-\mathrm{O}$ and three $\mathrm{Al}-\mathrm{N}$ bonds are formed with lengths of 1.832-1.942 $\AA$ and 1.982-2.020 $\AA$, respectively. The undissociated $\mathrm{N}-\mathrm{H}$ and $\mathrm{N}-\mathrm{O}$ bonds are elongated to 1.032-1.069 $\AA$ and 1.256-1.498 $\AA$, respectively, which is because the $\mathrm{N}$ and $\mathrm{O}$ atoms interact actively with the adjacent $\mathrm{Al}$ atoms. ${ }^{36}$ The corresponding adsorption energy of $6 \mathrm{~V}$ is $-1383.32 \mathrm{~kJ} \mathrm{~mol}^{-1}$, which is the highest energy in the vertical adsorption systems. $5 \mathrm{~V}$ exhibits the $\mathrm{C}-\mathrm{C}$ symmetric axis of the TATB molecule above the bridge site between the three layers of the Al surface. According to this site, chemical adsorption causes the dissociation of two $\mathrm{O}$ atoms from the same nitro group. $5 \mathrm{~V}$ is the substable structure in the vertical adsorption system studied, and its energy value is -398.072096 a.u. $\mathrm{C}_{6} \mathrm{~N}_{5} \mathrm{H}_{6} \mathrm{O}_{4}$, with two dissociated $\mathrm{O}$ atoms, and one dissociated $\mathrm{N}$ atom, which are adsorbed on the $\mathrm{Al}$ surface, results in the formation of six $\mathrm{Al}-\mathrm{O}$ and five Al-N bonds with the lengths of 1.848-1.876 ̊ and 1.945-2.117 A, respectively. Furthermore, the N-H and N-O bonds are lengthened to 1.039-1.065 $\AA$ and 1.258-1.267 $\AA$, respectively, in comparison with the initial values in Fig. 1(c). The adsorption energy of $5 \mathrm{~V}$ is larger by $207.97 \mathrm{~kJ} \mathrm{~mol}^{-1}$ than that of $6 \mathrm{~V}$, which shows that vertical adsorption leads to a higher adsorption energy and unstable system. $1 \mathrm{~V}, 2 \mathrm{~V}, 3 \mathrm{~V}$, and $4 \mathrm{~V}$ in Fig. 3 depict that the C-C symmetric axis of the ТАTB molecule is above an on-top site, a bridge site between the second layer of the $\mathrm{Al}$ surface, an fcc site, and an hcp site, 
Table 1 Selected bond lengths $(\AA)$ and atomic distances $(\AA)$ of the different TATB/Al (111) configurations

\begin{tabular}{|c|c|c|c|c|c|c|c|}
\hline Geometries & $\mathbf{P}^{a}$ & $1 \mathrm{P}$ & $2 \mathrm{P}$ & $3 \mathrm{P}$ & $4 \mathrm{P}$ & $5 \mathrm{P}$ & $6 \mathrm{P}$ \\
\hline N1-O11 & 1.261 & 2.753 & 1.387 & 1.422 & 1.456 & 1.422 & 2.647 \\
\hline N1-O12 & 1.260 & 1.393 & 1.424 & 2.630 & 2.555 & 2.576 & 1.429 \\
\hline N3-O31 & 1.260 & 1.473 & 1.416 & 2.671 & 1.456 & 2.593 & 1.504 \\
\hline N3-O32 & 1.261 & 1.373 & 2.724 & 1.442 & 2.563 & 2.716 & 2.841 \\
\hline N5-O51 & 1.259 & 1.422 & 3.510 & 2.738 & 1.458 & 1.405 & 1.419 \\
\hline N5-O52 & 1.259 & 2.915 & 1.482 & 1.531 & 2.557 & 1.387 & 2.617 \\
\hline \multirow[t]{9}{*}{$\mathrm{Al}-\mathrm{O}$} & & 1.823 & 1.831 & 1.816 & 1.811 & 1.788 & 1.806 \\
\hline & & 1.832 & 1.850 & 1.811 & 1.813 & 1.820 & 1.811 \\
\hline & & 1.833 & 1.851 & 1.813 & 1.814 & 1.830 & 1.829 \\
\hline & & 1.841 & 1.870 & 1.829 & 1.844 & 1.841 & 1.838 \\
\hline & & 1.844 & 1.876 & 1.832 & 1.846 & 1.843 & 1.839 \\
\hline & & 1.873 & 1.894 & 1.833 & 1.848 & 1.844 & 1.842 \\
\hline & & & & 1.850 & 1.848 & 1.844 & 1.861 \\
\hline & & & & 1.863 & 1.854 & 1.852 & 1.895 \\
\hline & & & & 1.870 & 1.855 & 1.855 & 1.942 \\
\hline \multirow[t]{3}{*}{$\mathrm{Al}-\mathrm{N}$} & & 1.990 & 2.005 & 2.092 & 1.957 & 1.931 & 1.995 \\
\hline & & 2.054 & 2.097 & & 1.958 & 1.961 & 1.995 \\
\hline & & & & & 1.965 & & 2.080 \\
\hline Geometries & $\mathrm{V}^{b}$ & $1 \mathrm{~V}$ & $2 \mathrm{~V}$ & $3 \mathrm{~V}$ & $4 \mathrm{~V}$ & $5 \mathrm{~V}$ & $6 \mathrm{~V}$ \\
\hline N1-O11 & 1.265 & 2.558 & 2.960 & 2.997 & 3.078 & 3.037 & 3.149 \\
\hline N1-O12 & 1.266 & 3.538 & 2.907 & 3.025 & 3.005 & 3.033 & 1.498 \\
\hline N3-O31 & 1.259 & 1.260 & 1.263 & 1.260 & 1.259 & 1.258 & 1.446 \\
\hline N3-O32 & 1.259 & 1.271 & 1.356 & 1.265 & 1.270 & 1.263 & 2.727 \\
\hline N5-O51 & 1.260 & 1.270 & 1.254 & 1.266 & 1.265 & 1.267 & 1.272 \\
\hline N5-O52 & 1.260 & 1.257 & 1.258 & 1.260 & 1.260 & 1.258 & 1.256 \\
\hline \multirow[t]{6}{*}{$\mathrm{Al}-\mathrm{O}$} & & 1.791 & 1.825 & 1.843 & 1.850 & 1.848 & 1.843 \\
\hline & & 1.859 & 1.834 & 1.847 & 1.852 & 1.854 & 1.850 \\
\hline & & 1.862 & 1.853 & 1.853 & 1.860 & 1.862 & 1.862 \\
\hline & & 1.865 & 1.872 & 1.866 & 1.864 & 1.863 & 1.873 \\
\hline & & 1.878 & 1.883 & 1.869 & 1.868 & 1.867 & 1.881 \\
\hline & & 1.906 & 1.885 & 1.884 & 1.880 & 1.876 & 1.942 \\
\hline \multirow[t]{3}{*}{$\mathrm{Al}-\mathrm{N}$} & & 1.901 & 1.868 & 1.967 & 1.987 & 1.945 & 1.982 \\
\hline & & 2.027 & 1.888 & 1.983 & 1.991 & 1.956 & \\
\hline & & 2.048 & & 1.984 & 1.993 & 1.987 & \\
\hline
\end{tabular}

${ }^{a}$ Configuration P refers to Fig. 1(b), in which there is no interaction between TATB and the $\mathrm{Al}$ (111) surface. ${ }^{b}$ Configuration V refers to Fig. 1(c), in which there is no interaction between TATB and Al the (111) surface.

respectively. The adsorption and dissociation modes of $1 \mathrm{~V}, 2 \mathrm{~V}$, $3 \mathrm{~V}$, and $4 \mathrm{~V}$ are in full agreement with that of $5 \mathrm{~V}$. At the on-top site, the formation of six $\mathrm{Al}-\mathrm{O}$ and four $\mathrm{Al}-\mathrm{N}$ bonds is caused by chemical adsorption, which have lengths of 1.791-1.906 $⿱ 亠 䒑$ and 1.901-2.048 $\AA$, respectively. At the hcp site, six Al-O and five Al-N bonds form with the lengths of 1.850-1.880 $\AA$ and 1.987$2.120 \AA$ A respectively. In addition, the chemical adsorption at the fcc site induces the formation of six $\mathrm{Al}-\mathrm{O}$ bonds with the length of 1.843-1.884 $\AA$ and five Al-N bonds with the length of

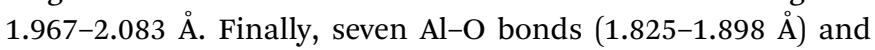
three $\mathrm{Al}-\mathrm{N}$ bonds (1.868-2.079 $\AA$ ) are formed by chemical adsorption at a bridge site between the second layer of the $\mathrm{Al}$ surface.

The structures of TATB are strongly affected by the surfaces of metal aluminum. The $E_{\text {ads }}$ of all the TATB/Al (111) systems are less than zero, indicating that the adsorption interaction process is exothermic between TATB and the Al surface. For parallel and vertical adsorption, TATB favors planar or quasiplanar structures. Moreover, TATB significantly changes the structures of the $\mathrm{Al}$ (111) surfaces. For the different adsorption sites, there are different decomposition products. Besides the stable Al-O bonds, Al-N bonds are also created by the active adsorption interaction between the $\mathrm{Al}$ atoms on the surface and $\mathrm{N}$ atoms in either the nitro group or the amino group. The fracture of $\mathrm{N}-\mathrm{O}$ bonds in the nitro groups and the formation of $\mathrm{Al}-\mathrm{N}$ and $\mathrm{Al}-\mathrm{O}$ bonds between dissociative $\mathrm{N}$ and $\mathrm{O}$ atoms and Al surface are the main way of dissociation adsorption (Fig. 4 and 5).

$5 \mathrm{P}$ is the second most stable configuration, which is higher in energy than 6P by 0.08791 a.u., and TATB is dissociated to $\mathrm{C}_{6} \mathrm{~N}_{3} \mathrm{H}_{6}, \mathrm{NO}_{2}, \mathrm{NO}, \mathrm{N}$, and 3O. The two $\mathrm{Al}-\mathrm{N}$ and twelve $\mathrm{Al}-\mathrm{O}$ bonds lengths are 1.931-1.961 $\AA$ and 1.788-1.882 $\mathrm{A}$, respectively. The $\mathrm{Al}-\mathrm{N}$ and $\mathrm{Al}-\mathrm{O}$ bond lengths are less than that of $6 \mathrm{P}$, which leads to an increase in its configuration energy. The elongation tendency of all the undissociated $\mathrm{N}-\mathrm{O}$ bonds is exactly the same as that of $6 \mathrm{P}$. The adsorption energy of $5 \mathrm{P}$ is the second highest among the adsorption energies $\left(-1646.86 \mathrm{~kJ} \mathrm{~mol}^{-1}\right)$, which is consistent with the results of the configuration energy. All the adsorption configurations are accompanied by fractures of the $\mathrm{N}-\mathrm{O}$ bonds in the nitro groups. In addition, there is also a hydrogen atom transfer for 5P. Fig. 6 illustrates the optimized structures of $5 \mathrm{P}$ during the various minimization steps, which was calculated using the PBEsol functional. From $a$ to $e$, with the energy optimization process, it is obvious that the total energy of the optimized structure of $5 \mathrm{P}$ drops significantly. Before $b$, there is no fracture of the chemical bonds for the TATB molecule, and only its molecular conformation is changed. Fig. 6 shows that the change in molecular conformation contributes to the greatest reduction in the energy of the system. At $b$, with a decrease in energy (72.87 $\mathrm{kJ} \mathrm{mol}^{-1}$ ), two N-O bonds (N1-O12, N3-O32) are broken, and the dissociated oxygen atoms form two Al-O bonds with aluminum atoms. From $b$ to $c$, the N5-O51 bond breaks in the third nitro group and an Al-O bond forms. Furthermore, at $d$, the N5-O51 bond forms again. From $e$ to $g$, with the

Table 2 Adsorption energies ( $E_{\text {ads }}$ ) of TATB on the Al (111) surface

\begin{tabular}{|c|c|c|c|c|c|c|}
\hline Configurations & $1 P$ & $2 \mathrm{P}$ & $3 P$ & $4 \mathrm{P}$ & $5 \mathrm{P}$ & $6 \mathrm{P}$ \\
\hline Adsorption sites & Bridge & Bridge & fcc & Top & hcp & Bridge \\
\hline$E_{\mathrm{ads}}\left(\mathrm{kJ} \mathrm{mol}^{-1}\right)$ & -1415.67 & -1511.88 & -1518.61 & -1531.33 & -1646.86 & -1877.67 \\
\hline Configurations & $1 \mathrm{~V}$ & $2 \mathrm{~V}$ & $3 \mathrm{~V}$ & $4 \mathrm{~V}$ & $5 \mathrm{~V}$ & $6 \mathrm{~V}$ \\
\hline Adsorption sites & Top & Bridge & fcc & hcp & Bridge & Bridge \\
\hline$E_{\text {ads }}\left(\mathrm{kJ} \mathrm{mol}^{-1}\right)$ & -1125.26 & -1126.97 & -1142.18 & -1167.29 & -1175.35 & -1383.32 \\
\hline
\end{tabular}



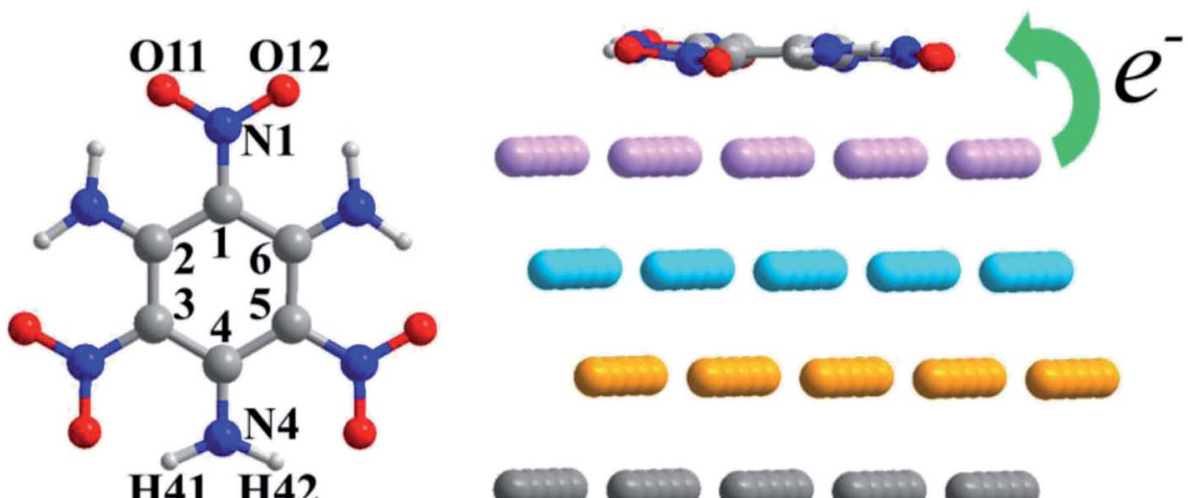

Fig. 4 Selected atomic number and electron transfer of TATB on the Al (111) surface: Nitrogen atoms are the same number as adjacent carbon atoms. In the counter clockwise direction, the oxygen atoms and hydrogen atoms are $\mathrm{O} 11, \mathrm{H} 21, \mathrm{H} 22, \mathrm{O} 31, \mathrm{O} 32, \mathrm{H} 41, \mathrm{H} 42, \mathrm{O} 51, \mathrm{O} 52, \mathrm{H} 61, \mathrm{H} 62$, and $\mathrm{O} 12$.
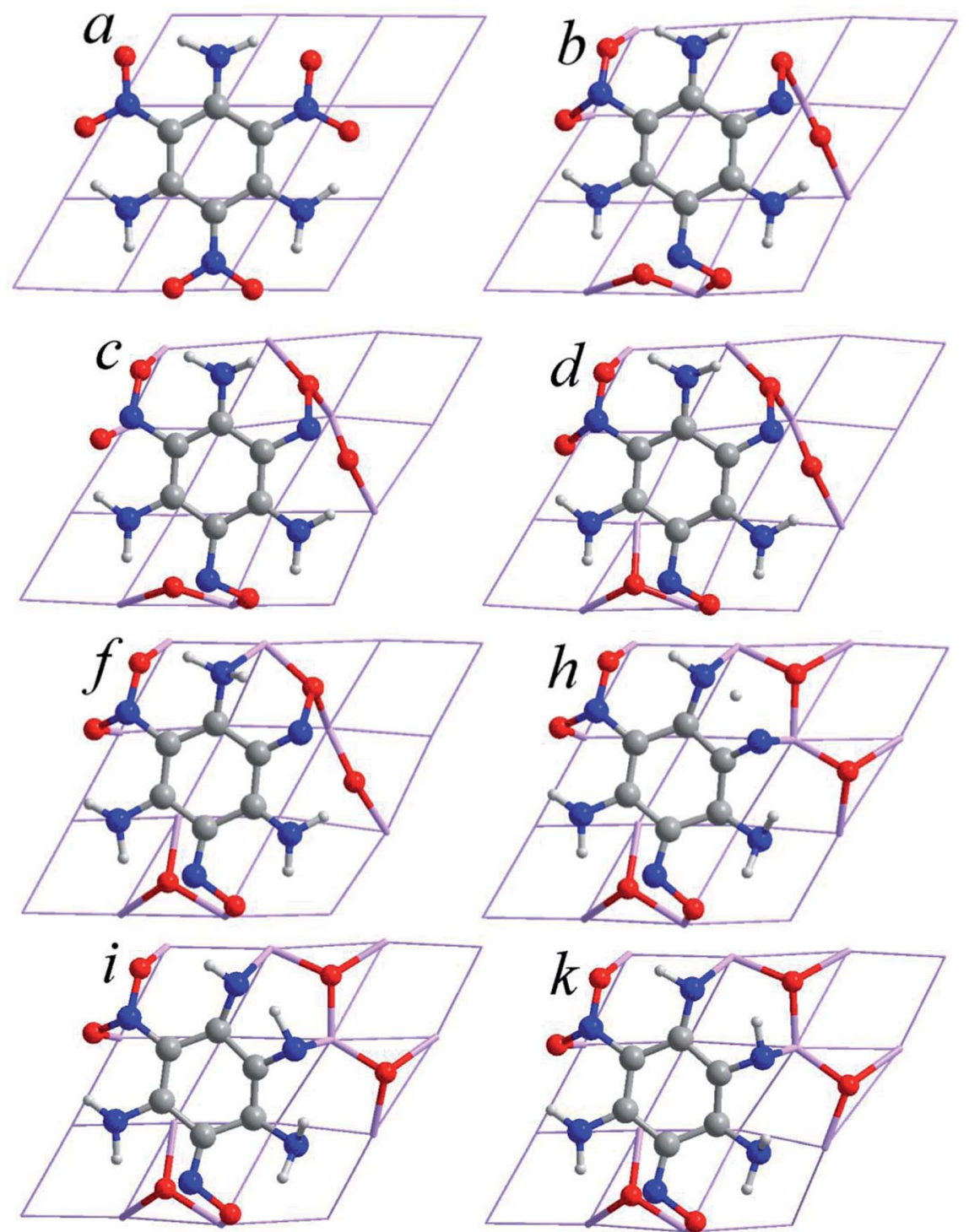

Fig. 5 Snapshots of points $b, c, d, f, h$, and $i$, corresponding to various stages of geometry optimization, where $a$ and $k$ represent the initial and final geometry of $5 \mathrm{P}$, respectively. 


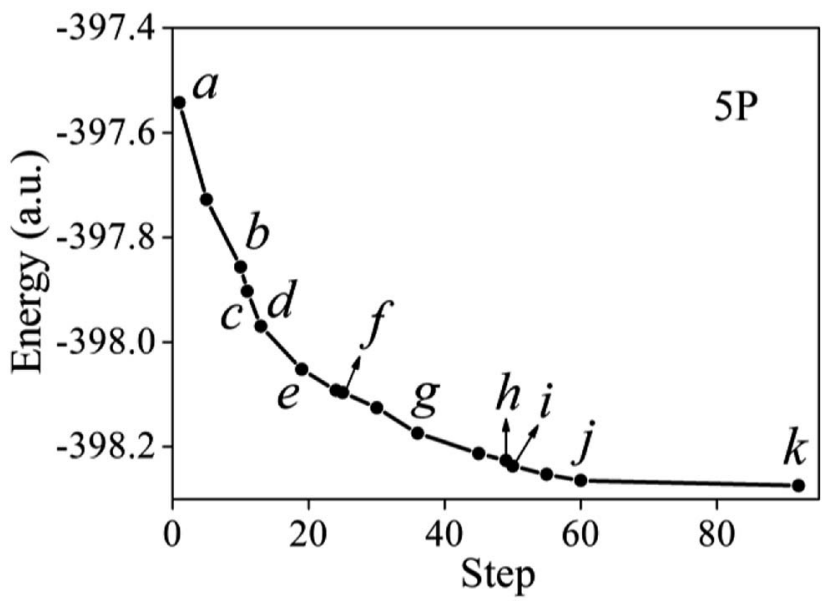

Fig. 6 Variation in the total energy with the optimization steps of 5P.

optimization of the adsorption configuration, the N1, N3, O12, $\mathrm{O} 31$, and $\mathrm{O} 32$ atoms interact with the aluminum atoms on the surface. At $f$, ten $\mathrm{Al}-\mathrm{O}$ and one $\mathrm{Al}-\mathrm{N}$ bonds form. Except the breakage of the N1-O1 and N3-O32 bonds, the N3-O31 bond also breaks with a reduction in energy $\left(5.50 \mathrm{~kJ} \mathrm{~mol}^{-1}\right)$, which
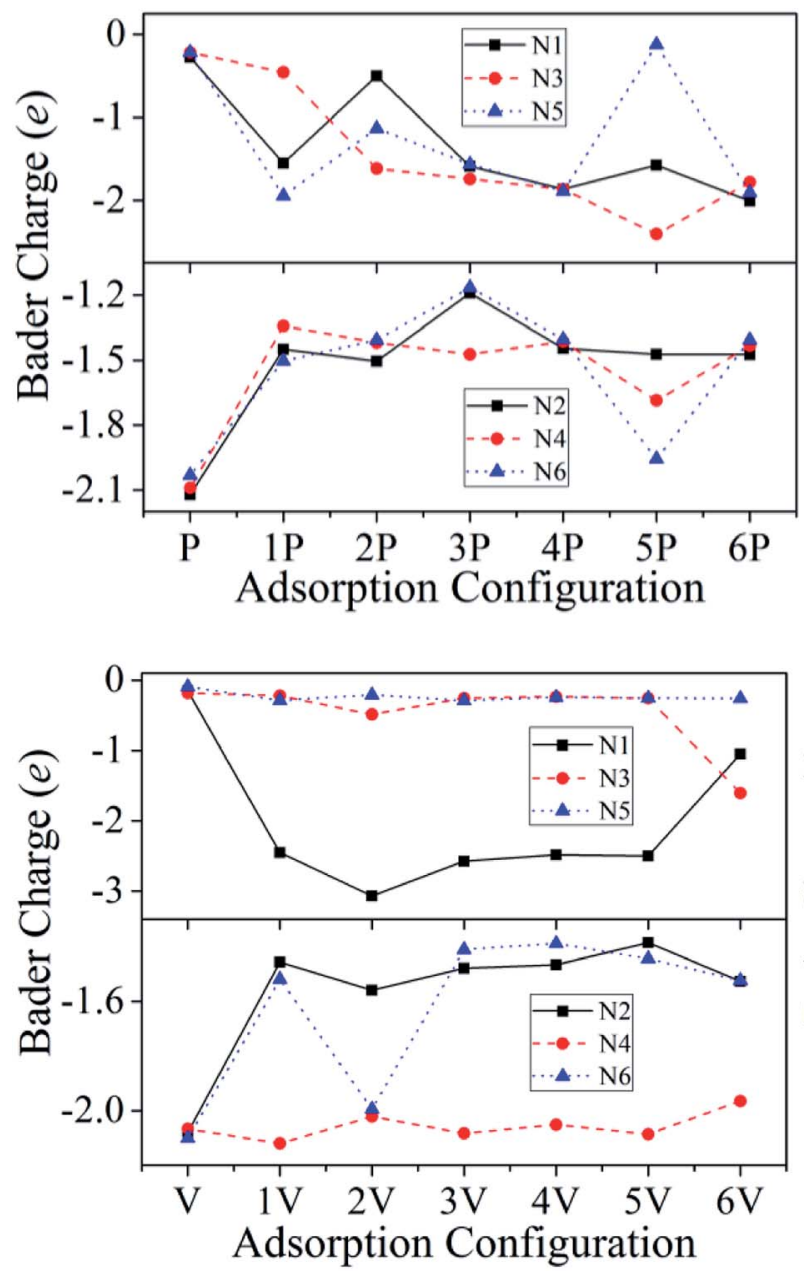

means that the two $\mathrm{N}-\mathrm{O}$ bonds from the same nitro group break. Compared with the fracture of the first $\mathrm{N}-\mathrm{O}$ bond, the second $\mathrm{N}-\mathrm{O}$ bond is not subjected to break in the same nitro group. After $g$, the energy reduces rapidly again. Furthermore, the energy is reduced by $19.28 \mathrm{~kJ} \mathrm{~mol}^{-1}$ from $h$ to $i$. A hydrogen atom from the N4 site of TATB detaches and reattaches to the nearby N3. Hydrogen transfer is also an important way to reduce the energy of the system. For $5 \mathrm{P}$, the main form of dissociation is the fracture of the first $\mathrm{N}-\mathrm{O}$ bond in each nitro group, accompanied by the transfer of hydrogen atoms.

\subsection{Electronic structure}

3.2.1 Charge distribution. Fig. 7 presents the Bader's charges $^{37}$ of the TATB/Al (111) configurations. In all of the configurations, charge transfer from the Al (111) surface to TATB was observed. From the Al (111) surface to the TATB molecule, the transfer of electrons of $4 \mathrm{P}(14.00 e)$ is the largest for parallel adsorption. This is because for $4 \mathrm{P}$, the center of the benzene ring is above an on-top site and there is maximum contact face to face between TATB and the $\mathrm{Al}$ atoms on the $\mathrm{Al}$ (111) surface. The interaction of all the $\mathrm{C}, \mathrm{H}, \mathrm{O}$, and $\mathrm{N}$ atoms with the surface $\mathrm{Al}$ atoms leads to the largest electron transfer.
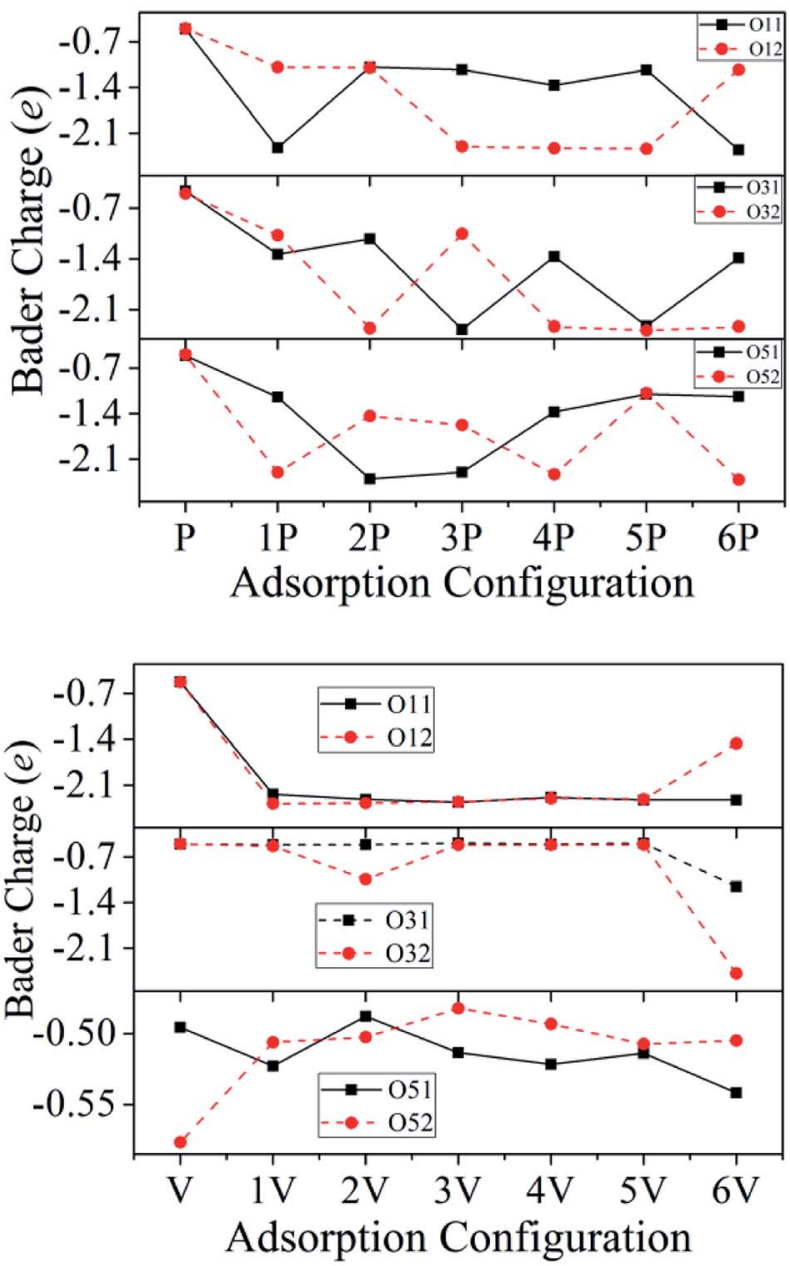

Fig. 7 Bader charges on the individual $N$, and $O$ atoms. Configurations $P$ and $V$ refer to Fig. 1 (b) and (c), respectively, in which there is no interaction between TATB and the Al (111) surface. 
The electron transfers of $1 \mathrm{~V}(7.60 e), 2 \mathrm{~V}(7.64 e), 3 \mathrm{~V}(7.73 e), 4 \mathrm{~V}$ (7.51e), and $5 \mathrm{~V}(7.57 e)$ are basically the same for vertical adsorptions. $6 \mathrm{~V}$ has the largest electron transfer (9.04e), which is because the TATB molecule changes from initially perpendicular to the aluminum surface to nearly parallel to the aluminum surface, which increases the interaction between the TATB molecule and aluminum surface. Fig. 7 shows that for 1P, $2 \mathrm{P}, 3 \mathrm{P}, 4 \mathrm{P}$, and $5 \mathrm{P}$, the charges of $\mathrm{N} 3$ rapidly decrease with an increase in the absolute energy value. For 2P, 3P, 4P, 5P, and 6P, the charges on $\mathrm{O} 31$ show oscillation behavior with an increase in the absolute energy value. The electrons obtained in $\mathrm{O} 32$ are basically equal for $4 \mathrm{P}(2.33 e), 5 \mathrm{P}(2.38 e)$, and $6 \mathrm{P}(2.33 e)$.

The largest number of electrons is obtained by $6 \mathrm{P}$, which is $2.01 e, 2.35 e$, and $2.41 e$ for $\mathrm{N} 1, \mathrm{O} 11$, and 052 , respectively. Each nitro group in the TATB molecule breaks one $\mathrm{N}-\mathrm{O}$ bond, which causes the largest degree of bond interaction between TATB and the $\mathrm{Al}$ (111) surface and charge transfer from the $\mathrm{Al}$ (111) surface to TATB. For 1P, the N5-O52 bond breaks and an N5-Al bond forms, which indicated that the $\mathrm{Al}$ surface transfers the most electrons to N5 (1.94e). Furthermore, N5 atom of 5P only obtains $0.12 e$, which is less than that of $\mathrm{P}(0.22 e)$. This is because the N5-O51 and N5-O52 bonds do not break. The N5O51 and N5-O52 bond lengths (1.405 $\AA$ and $1.387 \AA$, respectively) of $5 \mathrm{P}$ are longer than that of $\mathrm{P}$ (both are $1.259 \AA$ ). In addition, the N5 of 5P is farther away from the aluminum surface in comparison with that of $\mathrm{P}$, and has a weaker interaction force; therefore, the number of transferred electrons in $5 \mathrm{P}$ is less than that in P. Similarly, for N2, N4, and N6, the obtained electrons of $1 \mathrm{P}-6 \mathrm{P}$ are less than that of $\mathrm{P}$.

The charge evolution for vertical adsorption is remarkably different from that for parallel adsorption. $6 \mathrm{~V}$ obtained the largest number of electrons for $\mathrm{N} 3, \mathrm{O} 31$, and O32, which is $1.60 e, 1.15 e$, and $2.48 e$, respectively. The fracture of the covalent bond of N3-O32 leads to the formation of four Al-O bonds and the transformation of 2.41e. Also, the other TATB/Al (111) systems have little change in electron transfer. For $1 \mathrm{~V}-6 \mathrm{~V}$, the change rules of N5, O51, and O52 are consistent with that of N3, $\mathrm{O} 31$, and $\mathrm{O} 32$, and the electrons obtained in N2 and N6 are less than that of $\mathrm{V}$. For example, for $5 \mathrm{~V}$, the lengths of the $\mathrm{N} 2-\mathrm{H} 21$, N2-H22, N6-H61, and N6-H62 bonds are $1.062 \AA, 1.051 \AA, 1.056$ $\AA$, and $1.067 \AA$, respectively, which are longer than that of $\mathrm{V}$ (all $1.043 \AA$ ), demonstrating weaker valence bond interaction and less transferred electrons.

The number of transferred electrons in parallel adsorptions is larger than that of vertical adsorptions. The strong interaction between the $\mathrm{N}$ and $\mathrm{O}$ atoms in $-\mathrm{NO}_{2}$ and aluminum surface
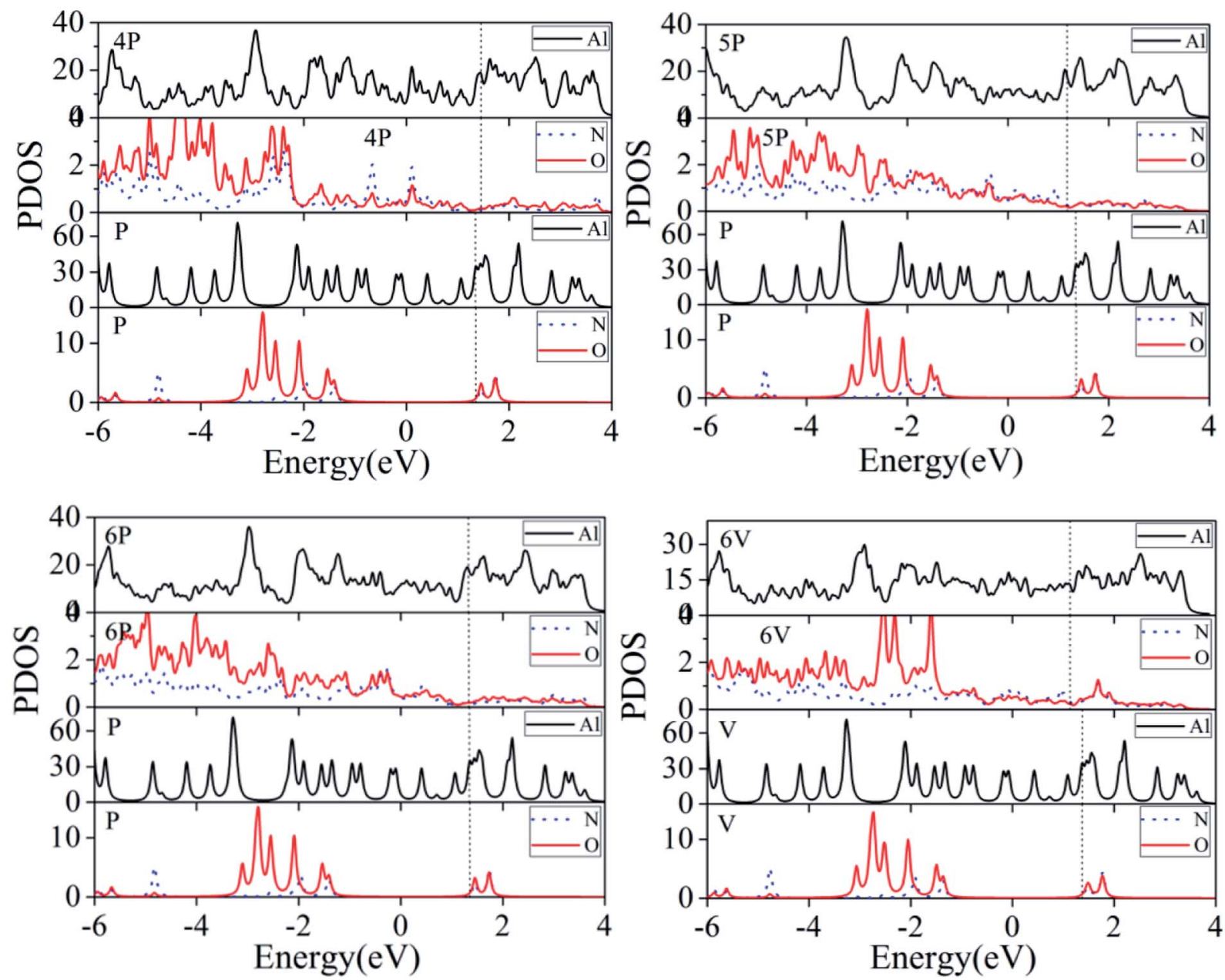

Fig. 8 Calculation of PDOS for P, 4P, 5P, 6P, V, and 6V. 
results in a nonuniform distribution of charges. Some $\mathrm{N}$ and $\mathrm{O}$ atoms get the largest number of electrons from the surface of aluminum, and simultaneously, the $\mathrm{N}-\mathrm{O}$ bond breaks, forming the internal hot spot of the system. The charge nonuniformity of TATB may be important for the activation of the TATB molecule adsorbed on the $\mathrm{Al}$ (111) surface.

3.2.2 Density of states. Fig. 8 presents the partial density of states (PDOS) of some of the TATB/Al (111) systems. As shown in Fig. 8, the top of the valence band and the bottom of the conduction band are mainly contributed by the $\mathrm{p}$ states from the $\mathrm{Al}$ atoms, which indicates that the $\mathrm{p}$ states play an irreplaceable role in terms of effect on the dissociative adsorption of TATB on the $\mathrm{Al}$ (111) surface. For the different TATB/Al (111) systems, the existence of good interactions is obvious between TATB and the Al (111) surface, particularly in the energy range from -7.0 to $0 \mathrm{eV}$, where the peak tendency is similar. Compared with the PDOS of $\mathrm{P}$, the PDOS (Al) of $4 \mathrm{P}, 5 \mathrm{P}$, and $6 \mathrm{P}$ changes slightly, but the small peaks increase, which is because the $\mathrm{Al}$ atoms transfer electrons from the $\mathrm{Al}$ (111) surface to TATB. In addition, the PDOS ( $\mathrm{N}$ and $\mathrm{O}$ ) peaks of $4 \mathrm{P}, 5 \mathrm{P}$, and $6 \mathrm{P}$ shift to a lower energy. This is consistent with the results from the PDOS of V and 6V. It is worth noting that there are two peaks of PDOS (O) of $\mathrm{P}$ at the Fermi energy, but it disappears in the PDOS $(\mathrm{O})$ of $4 \mathrm{P}, 5 \mathrm{P}$, and $6 \mathrm{P}$ due to the fracture of the $\mathrm{N}-\mathrm{O}$ bonds. From Fig. 8, the PDOS $(\mathrm{Al})$ peaks of $4 \mathrm{P}, 5 \mathrm{P}$, and $6 \mathrm{P}$ are higher than that of $6 \mathrm{~V}$, and the PDOS ( $\mathrm{N}$ and $\mathrm{O}$ ) peaks of $4 \mathrm{P}, 5 \mathrm{P}$, and $6 \mathrm{P}$ shift to a lower energy in comparison with that of $6 \mathrm{~V}$, indicating that the adsorption mode of the system is more inclined to parallel adsorption. Furthermore, the PDOS ( $\mathrm{N}$ and $\mathrm{O}$ ) peaks of $4 \mathrm{P}$ and $6 \mathrm{P}$ are higher than that of $5 \mathrm{P}$. This is because an oxygen atom is dissociated from each nitro group in the dissociation mode (2), which increases the interaction between the $\mathrm{Al}$ (111) surface and TATB. For $4 \mathrm{P}$, the center of the benzene ring is above an on-top site, which leads to the PDOS ( $\mathrm{N}$ and $\mathrm{O}$ ) peaks of $4 \mathrm{P}$ being higher than that of $6 \mathrm{P}$.

\section{Conclusions}

In summary, the adsorption modes and electronic structures of TATB/Al (111) systems were studied based on DFT calculations. The results indicated that the ТАТВ molecule rotates to maximize its interaction with the $\mathrm{Al}$ surface during the optimization. The TATB molecules prefer planar structures, which lay flat on the $\mathrm{Al}$ (111) surfaces. The dissociated oxygen atom in each nitro group interacts strongly with the aluminum atoms on the surface. In addition to the fractures of the $\mathrm{N}-\mathrm{O}$ bonds, the transformation of the hydrogen atom is also a form of dissociation adsorption of TATB on the $\mathrm{Al}$ (111) surface. In comparison with the fractures of chemical bonds, the changes of molecular conformation are easier to decrease the energy of the TATB/Al (111) surface. For the parallel adsorption configurations, the energy and adsorption energy of $6 \mathrm{P}$ are the lowest, which is -398.339594 a.u. and $-1877.67 \mathrm{~kJ} \mathrm{~mol}^{-1}$, respectively. For the vertical adsorption configurations, the energy and adsorption energy of $6 \mathrm{~V}$ are the lowest, which are -398.151305 a.u. and $-1383.32 \mathrm{~kJ} \mathrm{~mol}^{-1}$, respectively. The dissociative adsorption of TATB on the $\mathrm{Al}$ (111) surface is an exothermic process due to the negative adsorption energy. The parallel adsorption systems are more stable than the vertical adsorption systems. The TATB molecular skeleton of $6 \mathrm{~V}$ is approximately parallel to the $\mathrm{Al}$ surface, which also proves that the mode is more inclined to parallel adsorption. The adsorption systems are the most stable in dissociation mode (2), which are all parallel adsorption, and the adsorption systems are the most unstable in the dissociation mode (4), which are all vertical adsorption. The activation of TATB on the $\mathrm{Al}$ (111) surface and augmentation of the $\mathrm{N}$ and $O$ atom PDOS peaks are caused by the charge transfer from the Al (111) surface to the TATB molecule.

\section{Conflicts of interest}

There are no conflicts to declare.

\section{Acknowledgements}

This work was supported by Scientific and Technological Innovation Programs of Higher Education Institutions in Shanxi (No. 2016157), and Natural Science Foundation of Shanxi Normal University Modern College of Humanities and Sciences (No. 2018JCYJ03).

\section{References}

1 C. L. Jackson and J. F. Wing, Am. Chem. J., 1888, 10, 283.

2 H. H. Cady and A. C. Larson, Acta Crystallogr., 1965, 18, 485.

3 M. P. Kroonblawd and T. D. Sewell, J. Phys. Chem. C, 2016, 120, 17214.

4 T. D. Aslam, J. Appl. Phys., 2017, 122, 035902.

5 G. Z. Zhao and D. F. Yang, RSC Adv., 2018, 8, 32241.

6 S. Elbasuney, M. G. Zaky, M. Radwan and S. F. Mostafa, Appl. Surf. Sci., 2017, 419, 328.

7 D. Picart and A. Junqua-Moullet, Propellants, Explos., Pyrotech., 2017, 42, 1431.

8 C. Y. Zhang, Y. S. Wen, X. G. Xue, J. Liu, Y. Ma, X. D. He and X. P. Long, J. Phys. Chem. C, 2016, 120, 25237.

9 Y. S. Wen, C. Y. Zhang, X. G. Xue and X. P. Long, Phys. Chem. Chem. Phys., 2015, 17, 12013.

10 Z. H. He, J. Chen and Q. Wu, J. Phys. Chem. C, 2017, 121, 8227.

11 Y. S. Wen, X. G. Xue, X. P. Long and C. Y. Zhang, J. Phys. Chem. A, 2016, 120, 3929.

12 Q. Wu, H. Chen, G. L. Xiong, W. H. Zhu and H. M. Xiao, J. Phys. Chem. C, 2015, 119, 16500.

13 R. V. Tsyshevsky, O. Sharia and M. M. Kuklja, Molecules, 2016, 21, 236.

14 W. H. Zhu, X. M. Zhang, T. Wei and H. M. Xiao, J. Mol. Struct.: THEOCHEM, 2009, 900, 84.

15 Y. Xiong, J. Liu, F. C. Zhong, T. Xu and K. M. Cheng, J. Phys. Chem. A, 2014, 118, 6858.

16 L. Z. Zhang, S. V. Zybin, A. C. T. van Duin, S. Dasgupta, W. A. Goddard and E. M. Kober, J. Phys. Chem. A, 2009, 113, 10619.

17 N. Liu, C. Zhou, Z. K. Wu, X. M. Lu, B. Z. Wang and W. L. Wang, J. Mol. Graphics Modell., 2018, 85, 262. 
18 J. Li, S. H. Jin, G. C. Lan, X. Ma, J. Ruan, B. Zhang, S. S. Chen and L. J. Li, CrystEngComm, 2018, 20, 6252.

19 N. Zakiyyan, A. Q. Wang, R. Thiruvengadathan, C. Staley, J. Mathai, K. Gangopadhyay, M. R. Maschmann and S. Gangopadhyay, Combust. Flame, 2018, 187, 1.

20 A. L. Shoaf and C. A. Bayse, J. Comput. Chem., 2018, 39, 1236.

21 J. Y. Wu, Y. X. Huang, L. J. Yang, D. S. Geng, F. P. Wang, H. Q. Wang and L. Chen, ChemPhysChem, 2018, 19, 2683.

22 J. B. Delisio, X. L. Hu, T. Wu, G. C. Egan, G. Young and M. R. Zachariah, J. Phys. Chem. B, 2016, 120, 5534.

23 D. M. Zhang, H. Zou and S. Z. Cai, Propellants, Explos., Pyrotech., 2017, 42, 953.

24 H. Robatjazi, H. Q. Zhao, D. F. Swearer, N. J. Hogan, L. N. Zhou, A. Alabastri, M. J. Mcclain, P. Nordlander and N. J. Halas, Nat. Commun., 2017, 8, 27.

25 J. W. Bennett, J. L. Bjorklund, T. Z. Forbes and S. E. Mason, Inorg. Chem., 2017, 56, 13014.

26 N. Wang, J. H. Peng, A. M. Pang, T. S. He, F. Du and A. Jaramillo-Botero, J. Phys. Chem. C, 2017, 121, 14597.

27 L. Bian, Y. J. Shu, J. B. Xu and L. Wang, J. Mol. Model., 2013, 19, 131.
28 S. Q. Zhou, D. H. Li, W. Zhou, X. H. Ju and D. Y. Jiang, Surf. Rev. Lett., 2016, 23, 1650048.

29 D. C. Sorescu, J. A. Boatz and D. L. Thompson, J. Phys. Chem. $B, 2003,107,8953$.

30 F. G. Wang, R. Tsyshevsky, A. Zverev, A. Mitrofanov and M. M. Kuklja, J. Phys. Chem. C, 2017, 121, 1153.

31 J. P. Perdew, A. Ruzsinszky, G. I. Csonka, O. A. Vydrov, G. E. Scuseria, L. A. Constantin, X. Zhou and K. Burke, Phys. Rev. Lett., 2008, 100, 136406.

32 J. P. Perdew, K. Burke and M. Ernzerhof, Phys. Rev. Lett., 1996, 77, 3865.

33 A. S. Cooper, Acta Crystallogr., 1962, 15, 578.

34 M. K. Shukla and F. Hill, J. Phys. Chem. C, 2014, 118, 310.

35 S. Q. Zhou, F. Q. Zhao, X. H. Ju, X. C. Cheng and J. H. Yi, J. Phys. Chem. C, 2010, 114, 9390.

36 L. N. Wu, Z. Y. Tian and W. Qin, J. Phys. Chem. C, 2018, 122, 16733.

37 E. Sanville, S. D. Kenny, R. Smith and G. Henkelman, J. Comput. Chem., 2007, 28, 899. 